\title{
VIVIR PARA CONTAR: TRAYECTORIA ESTÉTICO- POLÍTICA DE EDUARDO GALEANO ENTRE 1955 Y 1976
}

Gabriel Montali ${ }^{55}$

RESUMEN: El objetivo general de este trabajo es analizar las condiciones de posibilidad y desarrollo del proceso de radicalización ideológica que signó la trayectoria estético-política de Eduardo Galeano hasta mediados de la década de 1970. El texto se propone reconstruir el periplo que lo condujo a convertirse tanto en un exitoso escritor, como en uno de los más importantes articuladores de redes de relaciones profesionales, artísticas y políticas al interior del campo intelectual latinoamericano. En específico el trabajo persigue, primero, precisar cómo repercutieron en su biografía los sucesos políticos nacionales e internacionales más relevantes del período. En segundo lugar, establecer cómo se incorporaron a su programa de escritura las corrientes de pensamiento en auge en aquella época. $\mathrm{Y}$ en tercer término, identificar las características estéticas e ideológicas más importantes de dicha propuesta. A estos fines, la estrategia de análisis se enfocará en la transformación del imaginario del autor a lo largo de esos años, y en los temas y recursos estilísticos con los que constituyó su programa de escritura.

Palabras clave: Intelectuales; Literatura; Política; Periodismo; Eduardo Galeano.

ABSTRACT: The general objective of this work is to analyze the conditions of possibility and development of the process of ideological radicalization that marked the aesthetic-political trajectory of Eduardo Galeano until the mid-1970s. The text aims to reconstruct the journey

\footnotetext{
${ }^{55}$ Licenciado en Comunicación Social por la Universidad Nacional de Córdoba (UNC) Y Magister en Creación Literaria por la Universitat Pompeu Fabra de Barcelona (España). Docente de la Licenciatura en Comunicación Social de la Universidad de Villa María (UNVM), y de las carreras de Contador Público y Recursos Humanos de la Universidad de Ciencias Empresariales y Sociales (UCES). Este trabajo forma parte de la tesis para acceder al grado de Doctor en Estudios Sociales de América Latina por el Centro de Estudios Avanzados de la UNC.
} 
that led him to become both in a successful writer, as in one of the most important articulators of networks of professional, artistic and political relations within the Latin American intellectual field. Specifically, the work pursues, first, to specify how the most relevant national and international political events of the period had an impact on its biography. Secondly, to establish how the currents of thought on the rise at that time were incorporated into their writing program. And thirdly, identify the most important aesthetic and ideological characteristics of said proposal. To this end, the analysis strategy will focus on the transformation of the author's imagination over those years, and on the stylistic themes and resources with which he constituted his writing program.

Keywords: Intellectuals; Literature; Politics; Journalism; Eduardo Galeano.

\section{Introducción}

En una noche de finales de junio de 1954, cuando hacía apenas algunos meses que militaba en el Partido Socialista de Uruguay (PSU), Eduardo Galeano fue testigo de un acontecimiento que signaría sus ideas, su literatura y sus objetivos de vida durante las décadas siguientes. Aquella fue una noche de gritos de rabia y angustia en las calles de Montevideo. El conjunto de la izquierda uruguaya se movilizaba en repudio al golpe de Estado que había depuesto al presidente guatemalteco Jacobo Arbenz. El papel protagónico que jugaron los Estados Unidos en la intervención militar, debido a que las políticas de la gestión de Arbenz afectaban los intereses de varias empresas norteamericanas, provocó una profunda fractura en el pensamiento socialdemócrata y antiimperialista de los sectores de la elite letrada a la que pertenecía el autor. Tanto es así que en las semanas siguientes se realizaron un conjunto protestas que conmovieron la memoria colectiva de la juventud. Según el testimonio de Galeano en Días y noches de amor y de guerra, "Mi generación se asomó a la vida política con aquella señal en la frente. Horas de indignación y de impotencia... (...) Yo tenía catorce años y nunca se me borró el impacto" (GALEANO, 2000, p. 20 y 21).

Ese cisma al que se refiere el autor, se profundizaría en el curso del período coadyuvado por dos factores que motivaron el intenso proceso de radicalización ideológica que atravesaron los núcleos letrados progresistas y de izquierda del país entre 1955 y 1976. El primero de esos factores fue 
Vivir para contar:

Trayectoria estético-política de Eduardo Galeano entre 1955 y 1976| 177

el creciente protagonismo que alcanzaron diversas prácticas y cosmovisiones autoritarias en la cultura política de la Banda Oriental. Si bien el recorrido histórico indica que en la primera mitad del siglo XX el país articuló niveles de consenso muy superiores a los del resto del Cono Sur, las investigaciones de Eduardo Rey Tristán (2005), César Tcach (2006), Marina Iglesias (2011) e Inés Nercesian (2013) muestran que la violencia no era un elemento ajeno a la praxis de los distintos sectores del arco político. Al respecto, los especialistas destacan el empleo recurrente de las denominadas Medidas Prontas de Seguridad (MPS), un mecanismo de Estado de excepción que, en contra de lo previsto por la ley, fue utilizado para reprimir las protestas del movimiento obrero y perseguir a los dirigentes que las encabezaban, en un sentido que se profundizaría desde la década de 1960 hasta hacer de ese recurso la regla primordial para la conservación del orden sociopolítico.

Por otra parte, el segundo factor fue la crisis económica que sufrieron los orientales desde $1953 .^{56}$ Originada a raíz de la caída internacional de los precios de las commodities, que afectó notablemente a un sistema productivo asentado casi en su totalidad en la producción agropecuaria, la crisis motivó el viraje hacia lo que hoy se conoce como el segundo ciclo del Estado uruguayo (FILGUEIRA ET ALL, 2003). El punto de partida de este proceso fue el triunfo de Partido Nacional en las elecciones de 1958. Desde entonces, y a ritmo creciente, se implementó una alternativa de liberalización conservadora que apuntó a resolver el estancamiento económico mediante políticas de ajuste, recorte de derechos civiles y represión de la protesta social. El nuevo rumbo se consolidó en 1967 con la asunción a la presidencia de Jorge Pacheco Areco, cuyo gobierno alineó definitivamente al país en la órbita de las doctrinas de contrainsurgencia impulsadas desde los Estados Unidos a los fines de contener el avance del socialismo en la región.

En el marco de este paulatino recrudecimiento de la violencia institucional, Galeano fue uno de los tantos intelectuales cuya trayectoria se caracterizó por un veloz desplazamiento ideológico desde un ideario socialdemócrata y reformista, hacia otro que definía a la revolución como

56 Según datos recabados por Benjamín Nahum (1998), entre 1955 y 1959 el crecimiento se estancó en un magro 0,3\% anual y el Estado acumuló un déficit de 258 millones de dólares. Esto se tradujo en una sensible baja en el nivel de empleo y en un incremento del costo de vida, pues la coyuntura desató una escalada inflacionaria que se mantuvo en el orden del 30\% y que alcanzó un pico del 135\% en 1967. 
la única vía capaz de modificar el orden establecido. Con ese horizonte de futuro imaginado, el autor desarrolló un programa literario y periodístico cuya función no sólo tuvo por objeto coadyuvar a construir una nueva sociedad, sino también aportar a la constitución de un hombre nuevo, libre y emancipado de las leyes del valor y de la mercancía. El rasgo distintivo de este programa fue la propuesta de una literatura peligrosa o de aspiración revolucionaria en base a tres ejes: la concepción del autor como impugnador del orden; la adopción de estéticas realistas como medio para operar esa interacción dialéctica entre praxis literaria y cambio social; y la consideración del arte como un instrumento necesario pero no suficiente para concretar transformaciones revolucionarias, pues para ello también resultaba imprescindible la intervención política del intelectual en la escena pública.

En ese tránsito, Galeano encontró en la Revolución Cubana (1959) el modelo para una transformación exitosa del sistema capitalista, a la vez que consideró a la figura martiriológica de Ernesto Guevara como la expresión más alta del compromiso militante - "la praxis misma del ser/estar haciendo la revolución”, según Ponza (2010, p. 136)-, porque el ejemplo de sacrificio del Che constituía la prueba fehaciente de que el activista estaba dispuesto incluso a ofrendar su propia vida en pos de la construcción de un mundo más justo. En concreto, para los núcleos de la izquierda intelectual latinoamericana, Cuba fue la novedad de la época en los términos en los que Víctor Goldgel (2013) ha definido la idea de lo nuevo: la emergencia de un ideal de ruptura con el pasado proyectado hacia un porvenir que se juzga auspicioso y posible, y cuya consecución se vive como una tarea necesaria que se realiza con entusiasmo. Claro que si Goldgel vinculó dicha idea al nacimiento de la modernidad y a la irrupción de la retórica optimista sobre el progreso, en plena etapa de fundación de los Estados nacionales, lo que Cuba representó como novedad fue la posibilidad de transformar radicalmente esa sociedad capitalista surgida entre los siglos XVIII y XIX. Y para ello ofrecía un método que se había mostrado efectivo: la definición de la lucha armada en tanto herramienta principal y más efectiva de acción política, y la idea de la voluntad revolucionaria del guerrillero como catalizador de la conciencia subjetiva de las masas.

Esta superposición entre el contexto local y la promesa romántica del logro cubano, conmovió el imaginario de la elite letrada a la que pertenecía el autor y se tradujo, por una parte, en un profundo cuestionamiento a la efectividad de la democracia para ofrecer una vía de 
Vivir para contar:

Trayectoria estético-política de Eduardo Galeano entre 1955 y 1976| 179 cambio radical de las condiciones de opresión del capitalismo. Y en segundo lugar, orientó a los núcleos de izquierda a buscar en los postulados marxistas las coordenadas de análisis de los fenómenos de la época. En rigor, en esos años entraron en auge tres vertientes teóricas que se caracterizaron por reinterpretar las ideas de Marx, desde una óptica que definía al campo de la cultura como un escenario clave en la lucha revolucionaria, que consideraba al hombre de ideas como un sujeto comprometido con una activa función de crítica al poder, y que entendía al subdesarrollo como el producto de un orden mundial que permitía que las potencias se apoderaran de los recursos generados en los países periféricos. Nos referimos al marxismo humanista de Antonio Gramsci, al pensamiento existencialista de Jean-Paul Sartre y a las teorías de la dependencia, tres aparatos argumentativos que jugaron un papel central en el pensamiento y el programa de escritura de Galeano. ${ }^{57}$

La enorme y acelerada difusión que alcanzaron tanto los ideales de transformación social como los argumentos de estas vertientes teóricas, también resultó favorecida por las políticas de Estado de Bienestar que aplicaron los gobiernos populares y desarrollistas del Cono sur entre las décadas de 1940 y 1950. Éstas repercutieron en un notable fortalecimiento del campo cultural gracias a la expansión de las matrículas universitarias y a la explosión del mercado de los libros, diarios y revistas. El denominado boom que fomentaron editoriales como EUDEBA y publicaciones como Marcha, Primera plana y Crisis, se asentó en la emergencia de nuevos públicos sumamente interesados en los debates sobre las problemáticas de la región. ${ }^{58}$ Lo dicho alimentó el surgimiento

\footnotetext{
${ }^{57}$ Debido a que existe una importante cantidad de estudios sobre estas corrientes, sólo nos detendremos a analizar en ellas las características que estén vinculadas con la literatura del autor. Para más información, consultar los trabajos de Pablo Ponza (2010), María Laura Maccioni (2011), Claudia Gilman (2012) e Inés Nercesian (2013).

${ }^{58}$ Fundada por Carlos Quijano en 1939, y dirigida por Galeano entre 1961 y 1964, Marcha fue una revista pionera en la articulación de temáticas de política y cultura, como así también en el intento de asociar a las elites letradas del continente a través de un conjunto de ideas y proyectos en común. Por su parte, Crisis, que también tuvo a Galeano como jefe de redacción, retomó el legado latinoamericanista y antiimperialista de Marcha, pero desde una perspectiva de mayor afinidad con los métodos y objetivos de las organizaciones político-militares de la época. Para más información sobre Crisis, consultar los trabajos de Pablo Ponza y Ramiro Zó incluidos en este dossier.
} 
de innumerables proyectos periodísticos y literarios abocados a temáticas político-culturales; proyectos que sentaron las bases para la constitución de una formidable red de relaciones entre intelectuales de todo el continente, que tuvo como eje articulador a la revista-editorial cubana Casa de las Américas.

Galeano se insertó en estos circuitos a muy temprana edad. A los catorce años comenzó a trabajar como dibujante para el semanario El sol, órgano oficial del PSU. Dos años más tarde, Carlos Quijano lo incorporó como colaborador de la revista Marcha. Así, el autor hizo su ingreso a la vida pública desde espacios contrahegemónicos del campo cultural, espacios que se destacaban por una férrea oposición al modelo aristocrático del hombre de ideas y por el intento de definir un nuevo paradigma estéticopolítico. Para un joven que había sido educado en los valores democráticos e igualitarios que habían caracterizado al movimiento reformista, ${ }^{59}$ la inserción en estos circuitos representó la posibilidad de entrar en contacto con las figuras más importantes de la izquierda letrada del país. En el curso de esos años, intelectuales como Mario Benedetti, Juan Carlos Onetti, Carlos Quijano, Raúl Sendic y Vivian Trías, no sólo enriquecieron su formación periodística y literaria, sino que además moldearon su pensamiento desde una perspectiva latinoamericanista, antiimperialista, crítica con ciertas prácticas asociadas a la moral burguesa -elitismo, consumismo, materialismo- y fuertemente identificada con las teorías de la dependencia.

Como veremos a lo largo del texto, la existencia misma de esos circuitos de interconexión, el entrenamiento en la gestión de proyectos culturales y la multiplicidad de contactos políticos que estas experiencias le aportaron, sumadas a la manera creativa e innovadora con que Galeano adaptó las corrientes de pensamiento de la época a su literatura, pueden considerarse como las variables explicativas tanto de su éxito comercial como de la relevancia de su figura para la consolidación del entramado de relaciones que forjaron en esos años los colectivos intelectuales de América Latina.

59 Esta corriente que operó como unificador ideológico de las elites letradas del Cono Sur hasta mediados de la década de 1940. Con raíces en la Reforma Universitaria de 1918, en la experiencia de los gobiernos uruguayos de José Batlle y Ordoñez (1903-1907 y 1911-1915) y en la obra de intelectuales como José Rodó, Rubén Darío y José Martí, el reformismo constituyó una pan-identidad que afirmaba reivindicaciones igualitarias entre las clases y que tendía puentes entre ideas democráticas, humanistas, liberales, socialistas y antiimperialistas. 


\section{Hacia la constitución de un programa de escritura}

Eduardo Germán María Huges Galeano nació en Montevideo el 3 de septiembre de 1940. Sus padres eran descendientes de la aristocracia fundadora del país. El linaje de su madre se remontaba al caudillo del Partido Colorado Fructuoso Rivera, quien fue el primer presidente constitucional de la República y compañero de armas de José Gervasio Artigas en las guerras civiles del siglo XIX. En tanto que su padre descendía de inmigrantes ingleses que habían jugado un papel protagónico en la fundación del Uruguay moderno. El más destacado de estos pioneros fue Richard Bannister Huges, quien entre las décadas de 1850 y 1860 fue integrante de la Comisión de Cuentas del Banco Central, vicepresidente de la Junta Consultiva de Gobierno y Hacienda y una destacada personalidad en el ámbito de la cultura, ya que fundó la ciudad de Fray Bentos, realizó la primera traducción al inglés del Martín Fierro y fue uno de los impulsores de la reforma de la educación que introdujo la enseñanza laica en las escuelas.

De acuerdo con testimonios recopilados por Fabián Kovacic en Galeano. Apuntes para una biografia (2015), sus familiares afirman que desde niño Eduardo mostró aptitudes para el dibujo y la escritura, unidas a una oratoria cautivante y a un carácter crítico y mordaz con ciertos esquemas morales de la sociedad de la época. Uno de los entrevistados lo recuerda a sus quince años en medio de una reunión familiar, defendiendo la importancia del amor libre y de las relaciones sexuales prematrimoniales "con una naturalidad que dejó estupefactas a todas las mujeres" (KOVACIC, 2015, p. 49). El propio autor comentó, en un reportaje con César Di Candia (1987, p. 32 y 33), que su niñez y su juventud estuvieron signadas por una suerte de "necesidad de trascendencia", que a menudo se tradujo en "una búsqueda desesperada de respuestas para ciertos interrogantes" existenciales:

Desde los 13 o 14 años yo empecé a trabajar y a militar [en] desafío a una realidad en la cual no lograba reconocerme y que quería cambiar. Era una realidad que quería cambiar, no tanto desde el punto de vista de la miseria, porque Uruguay en estos años no tenía miseria... pero era una sociedad incapaz 
de aventura, incapaz de intensidad, de una mediocridad repulsiva, ganada por el conformismo (GALEANO, apud PALAVERSICH, 1995, p. 7 y 8).

De ahí en adelante, su biografía se destaca por la toma de decisiones que Galeano juzgaba coherentes con el gesto ético de buscar otra vida, esto es, de vivir acorde a esos valores de justicia e igualdad que a su criterio habían sido extirpados por el capitalismo. La primera de esas decisiones fue su incorporación en 1954 a las filas del PSU. Allí trabó amistad con los dos referentes más importantes del proceso de radicalización ideológica y renovación dirigencial que atravesaba el socialismo uruguayo. Uno de ellos era el sindicalista Raúl Sendic, fundador en la década de 1960 del Movimiento de Liberación Nacional Tupamaros (MLN-T). El otro era el historiador Vivián Trías, cuya amalgama de ideas nacionalistas, revisionistas, marxistas y antiimperialistas influyó notablemente en el posicionamiento político del autor, quien desde entonces comenzó a adoptar la impronta que luego plasmó en Las venas abiertas de América Latina (1971).

Este deseo de vivir una vida contraria a los ideales de la moral burguesa, se extendería al desarrollo de un programa de escritura que consideraría al arte como una búsqueda humana antes que un ejercicio meramente estético. Se trata de una cosmovisión elaborada sobre la base de dos premisas que constituyen la esencia política de la literatura de Galeano. La primera es la búsqueda del sentido de la existencia en tanto principio de legitimidad y fundamento del acto de escribir, en una dinámica que se politizó al situar obra y vida en los marcos de un proyecto colectivo. La segunda, por su parte, es la concepción de la literatura como una práctica cuya razón de ser era la crítica integral del orden vigente, lo cual no sólo implicaba la denuncia de hechos concretos, sino también el cuestionamiento de todas las facetas de la vida que se veían afectadas por el capitalismo: el amor, las relaciones familiares, laborales, etcétera.

Desde esta óptica, y en sintonía con las exégesis de Sartre y Gramsci, el carácter hegemónico de la dominación hacía del campo cultural un escenario clave en la lucha revolucionaria. En efecto, la idea de que el orden no se asentaba sólo en el uso de la fuerza, pues la clase dirigente poseía la capacidad de instalar discursos que legitimaban una determinada línea de desarrollo de la sociedad, hacía necesario emprender una disputa ideológica en pos de subvertir esas concepciones. 
Vivir para contar:

Trayectoria estético-política de Eduardo Galeano entre 1955 y 1976| 183

De allí que escritores como Galeano atribuyeran a la literatura un papel protagónico en ese proceso: el papel de discutir esos discursos y de revelar los verdaderos intereses que los mismos ocultaban; como así también que definieran al intelectual como un sujeto comprometido con un rol de crítica al poder, es decir, como alguien que se asumía responsable frente a las problemáticas de la sociedad de su tiempo.

Estas premisas componen la base temático-estructural de la prosa de Galeano desde su primera producción, la novela Los días siguientes. Publicada en 1963, el eje argumental de sus páginas es el cuestionamiento del mito que definía a la Banda Oriental como un país de excepción. Tal como había hecho Benedetti en dos textos que resultaron decisivos para la trayectoria de Galeano, la novela La tregua (1960) y el ensayo El país de la cola de paja (1960), dicho propósito se desarrolla a partir del contraste con aquello que los núcleos de izquierda comenzaban a calificar como el colapso de los valores morales del país. En efecto, en esas páginas el autor cuenta la historia de un grupo de jóvenes desilusionados con el individualismo conformista de un entorno que no brindaba ningún tipo de expectativas a la juventud, fuera en el plano de la realización profesional o en la emergencia de proyectos colectivos que enriquecieran su mundo interior. Lo dicho se retrata desde la configuración de un escenario estático, despersonalizado y alienante, en el que todo parece previsible y en el que no hay lugar para la existencia de relaciones humanas auténticas, pues la falta de compromiso hace fútil el esfuerzo por empatizar con el otro y ni el amor ni la amistad logran aliviar la enajenación que causa ese entorno materialista, banal, exento de la épica que otorga la búsqueda de objetivos trascendentales:

Hablábamos del río, quizás, mientras remábamos (...); pero nunca de política ni de cuestiones de estudio o de trabajo. La vida de los demás trascurría alrededor; cada cual la miraba por su cuenta, a su manera, casi sin comentarios. (...) Había llegado a la altura en la que todo parecía previsible, el minutero seguía en marcha, los días se sucedían a los días (...). Pensar que la historia pudiera repetirse al infinito, era una idea que no podía soportar (GALEANO, 1963, p. 16 y 33). 
De acuerdo con Marchesi y Yaffé (2010), esta sensación de colapso moral estuvo motivada por la superposición entre la crisis económica y el incremento del autoritarismo en las políticas estatales. Desde esta perspectiva, la estructura de sentimientos que recrean obras como Los días siguientes o La tregua, constituyó uno de los principales leudantes de la crítica a la democracia republicana y de la adhesión de los núcleos de izquierda a tipologías radicales de lucha política. Sin embargo, la novela a su vez reconstruye un episodio clave en la vida del autor; un episodio que permite apreciar en toda su magnitud la potente ilusión que promovió la gesta cubana, como así también la importancia de las redes intelectuales en tanto espacios de pertenencia y contención.

En 1959, cuando estaba a punto de cumplir veinte años, Galeano sentía que su carrera como periodista y escritor no acababa de despegar. La falta de un trabajo estable en el campo periodístico y la pésima situación económica del país, cuyas tasas de desempleo e inflación crecían a un ritmo incontrolable, lo obligaban desde hacía cinco años a trabajar como empleado bancario. Además acababa de casarse y su esposa esperaba una hija. Poco a poco comenzó a sentir que su rutina lo alejaba de las expectativas sociales, artísticas y políticas que deseaba para su futuro, y cayó en una profunda depresión. "Se me había roto el espejo", cuenta Días y noches de amor y de guerra (2000, p. 49), porque no encontraba un proyecto de vida en el cual reflejarse, un proyecto que le hiciera creer que la vida valía la pena; y fue por eso que tomó una drástica decisión: alquiló un cuarto en un hotel e intentó suicidarse con una sobredosis de barbitúricos. Lo salvaron los empleados del establecimiento, que lo rescataron moribundo y lo llevaron a un hospital antes de que fuera demasiado tarde.

La anécdota se recrea en Los días siguientes a través del suicidio del personaje de Carlos, que coincide en sus detalles con el episodio vivido por el escritor. Finalmente, tras pasar varios días en coma, Galeano retomó sus actividades con el ánimo recompuesto. Según su testimonio: "veía al mundo por primera vez y me lo quería comer" (GALEANO, 2000, p. 50). Pero sea como haya sido ese proceso, lo cierto es que tres factores coadyuvaron a la superación de la crisis emocional que lo había conducido a esa experiencia extrema. El primero y más importante fue la Revolución Cubana, que pareció indicar el advenimiento de lo que Alan Badiou (2005) definió como una época prometeica, la época del hombre nuevo y de la inevitable transición del continente al socialismo. El segundo 
Vivir para contar:

Trayectoria estético-política de Eduardo Galeano entre 1955 y 1976| 185

fue el cierre de la fase de recambio generacional dentro de las estructuras PSU, que se concretó cuando Vivian Trías asumió la presidencia del partido en 1960, y que consistió en el reemplazo de los viejos caudillos socialdemócratas por jóvenes que hallaban un nuevo ejemplo a seguir en la poderosa eficacia de la gesta cubana. Y el tercero, por último, fue la mudanza del escritor a Buenos Aires ese mismo año para incorporarse al staff la revista Che, que dirigían Julia Constela y Pablo Giussani y en la que trabajaban intelectuales como David Viñas, Rodolfo Walsh y Juan Carlos Portantiero. ${ }^{60}$

Estos factores implicaron para Galeano la posibilidad de insertarse dentro de grupos que pujaban por un proyecto político renovador; un proyecto que parecía dar respuesta a las dudas existenciales que lo habían llevado a intentar quitarse la vida. En palabras de Diana Palaversich (1995), en torno al ideal romántico y altruista de la liberación nacional, en torno al compromiso con la construcción de una sociedad más justa, el escritor reorganizó sus inquietudes desde la sensación de sentirse parte de un fenómeno colectivo considerado superior, esto es, de un proyecto político que por fin garantizaba una opción de trascendencia individual al tener como horizonte un acto generoso, justo, un acto cuyo objetivo era terminar con el sometimiento y la miseria.

Pero si Cuba fijó la estrategia a seguir para alcanzar ese horizonte de expectativas, parece haber sido en los espacios materiales de las redes donde los intelectuales pudieron experimentar el sentido de pertenencia a ese proyecto superior. Según afirman Fernanda Beigel (2003) y Claudio Maíz (2011), los vínculos que éstas promovieron entre los hombres de ideas habrían generado una potente trama afectiva, una suerte de memoria en movimiento. Así, las redacciones, los centros culturales y otros espacios de reunión, muchas veces habrían funcionado de acuerdo a lo que Reinaldo Laddaga (2006) calificó como comunidades experimentales, es decir, como territorios en los que se intentaba construir otro tipo de vínculos entre las personas, casi a la manera del retorno a las nociones de fidelidad, horizontalidad y gratitud que Georg Simmel (2002) definió como un estar juntos por fuera de las coerciones del lucro y del poder. Y es

60 Che fue un espacio de articulación de discursos críticos que abrevaban en tradiciones político-culturales diversas pero que compartían las expectativas de cambio que Cuba acababa de introducir en el continente, lo cual exponían de manera directa en el homenaje que hacía el nombre de la publicación a la figura de Ernesto Guevara. 
por eso que las redes pueden pensarse como pequeños territorios ganados al sistema capitalista. Lugares en los que el afecto y el sentir de un algo en común parecen haberse vivido como la experiencia anticipada de una nueva sociedad. De allí la intensidad del recuerdo en la memoria de quienes fueron sus integrantes, como sucede en un fragmento de Días y noches... en el que Galeano evoca su paso por la revista Crisis y por el diario Época:

Vacío los cajones del escritorio, repletos de papeles míos y de cartas. Releo, al azar, palabras de mujeres que amé y de hombres que fueron mis hermanos. (...) Ha caído la noche. Los compañeros se han marchado hace un par de horas o hace meses. Los escucho, los veo; sus pasos y sus voces, la luz que cada uno irradia y el humito que deja cuando se va. (...) En el diario Época, en Montevideo, también era así. Uno entraba en aquella redacción de chiquilines y se sentía abrazado (...). ¿Quién podría olvidar a esos lindos tipos? ¿No reconozco aquel pulso, aquel sonido, en mi gente de ahora? ¿Sirve para algo, mi memoria? Hemos querido romper la máquina de mentir... La memoria. Mi veneno, mi comida (GALEANO, 2010, p. 174-176).

\section{La importancia de los circuitos periodísticos en la trayectoria del autor}

El periodismo, entonces, jugó un papel fundamental en el ascenso de su figura. Primero, porque constituyó un ámbito decisivo para la creación de redes de relaciones entre los intelectuales latinoamericanos, en una época en la que los libros y la prensa gráfica eran la principal fuente de acceso a la información. Y segundo porque, como veremos más adelante, de allí extrajo las herramientas discursivas que caracterizaron su literatura. Recordemos que esta circunstancia resultó favorecida por el boom editorial que vivió el continente desde finales de la década de 1950. Autores como Pablo Alabarces (2000), Andrea Giunta (2008), Pablo 
Vivir para contar:

Trayectoria estético-política de Eduardo Galeano entre 1955 y 1976| 187

Ponza (2010) y Claudia Gilman (2012), destacan la importancia que tuvieron en ese sentido las políticas redistributivas de los modelos de Estado Benefactor, que repercutieron en el crecimiento de las clases medias y, por consiguiente, en la expansión del mercado de consumo de bienes culturales.

En efecto, la década de 1960 estuvo signada por la irrupción de nuevos públicos sumamente ávidos por consumir los libros, discos, diarios y revistas que ahora se vendían incluso en plena calle, en los quioscos y comercios cuya multiplicación alteraba el paisaje de la ciudad. Se trata de públicos que comenzaron a mostrarse cada vez más interesados por las problemáticas de la época, y que en buena medida desplegaron ese interés desde una posición ideológica antiimperialista y rebelde. Es decir, una posición que observó con grandes expectativas el conjunto de sucesos nacionales e internacionales que parecían demostrar que el continente atravesaba un estadio prerrevolucionario.

Como señala Gilman (2012), esta circunstancia aceleró la profesionalización del campo cultural, pues las nuevas condiciones de producción y circulación ampliaron las posibilidades para hacer del ejercicio creativo un trabajo de tiempo completo. Ejemplo de este fenómeno fue el hito que significó la fundación de la Editorial de la Universidad de Buenos Aires (EUDEBA) en 1958, que entre ese año y 1962 publicó alrededor de tres millones de libros, convirtiéndose en la editorial universitaria más grande del mundo. A ello cabe agregar, por una parte, la notable expansión del espectro mediático gracias a la emergencia de diarios y revistas que a su vez multiplicaron la oferta laboral. Y por otra, el incremento significativo en los índices de venta de la producción literaria, que contó con records como los cien mil títulos vendidos por Gabriel García Márquez en 1967 con la publicación de Cien años de soledad.

En el caso del periodismo, el suceso que representaron revistas como Primera Plana, Marcha, Panorama o Crisis, todas ellas con tiradas de entre veinte y cuarenta mil ejemplares, y diarios como La Opinión o Noticias, que triplicaron ese promedio, ofreció además una tribuna de enorme repercusión para el posicionamiento ideológico de los hombres de ideas. ${ }^{61}$ Una tribuna que paralelamente vio reafirmada su función

${ }^{61}$ Para más información sobre el crecimiento en los índices de venta y las nuevas oportunidades que pasó a ofrecer en esos años el campo mediático, consultar el trabajo Paren las rotativas (2005), de Carlos Ulanovsky. 
mediadora entre la sociedad civil y el Estado a raíz de las circunstancias políticas. De acuerdo con los estudios de Carlos Demasi (1996) y Eduardo Rey Tristán (2005), la praxis autoritaria que se impuso durante los gobiernos de Jorge Pacheco Areco y Juan María Bordaberry, se tradujo entre otras cosas en sesenta y seis acciones de clausura perpetradas entre 1967 y 1973 contra treinta y seis medios de comunicación. De allí que la prensa se convirtiera tanto en un actor clave para la denuncia de los atropellos del poder, como en un espacio de visibilización del compromiso social de los escritores-intelectuales. ${ }^{62}$

La biografía de Galeano es un reflejo de este fenómeno, pues fue el periodismo la actividad que le granjeó el acceso a los circuitos letrados de la izquierda latinoamericana. Ahora bien, ¿cómo hizo el autor para convertirse en un referente dentro del campo cultural? Una primera variable es el complemento entre su trayectoria como director de proyectos periodísticos y sus viajes por el continente y el resto del mundo. Ambos factores configuraron su perfil de escritor y editor al tiempo que moldearon su perspectiva ideológica, le permitieron adquirir experiencia en la compleja tarea de organizar y dirigir emprendimientos culturales, y le aportaron la enorme red de contactos que nutriría su literatura en las décadas siguientes.

Dos hitos en esa trayectoria fueron sus desempeños como jefe de redacción del semanario Marcha (1961-1964) y del diario Época (19641967). Fundadas y dirigidas por Carlos Quijano, estas publicaciones nacieron como medios de expresión de una izquierda reformista y contrahegemónica, opuesta tanto a la concepción aristocrática del hombre de ideas como a los centros de legitimación de la cultura oficial. Para ello buscaban tener impacto en las inquietudes políticas del público a través de una estética desenfadada, atrevida e imaginativa; una estética que definía a los intelectuales como sujetos decididos a intervenir en las problemáticas de su tiempo, pero desde una óptica que ante todo aspiraba a profundizar las bases del régimen democrático. Tanto es así que su cosmovisión poco a poco fue relegada por tendencias que comenzaron a asociar el logro de cambios radicales al papel protagónico de la lucha revolucionaria.

62 Recordemos que en esos años se mantuvo prácticamente ininterrumpida la aplicación del Estado de sitio a través del implemento de Medidas Prontas de Seguridad. En dicho marco, las fuerzas policiales del país asesinaron en distintas manifestaciones a los estudiantes Líber Arce, Hugo de los Santos, Susana Pintos, Heber Nieto, Julio Spósito, Joaquín Klüver y al obrero municipal Arturo Recalde. 
Vivir para contar:

Trayectoria estético-política de Eduardo Galeano entre 1955 y 1976 | 189

Con respecto al semanario, Kovacic (2015) y Martín Ribadero (2014) afirman que más allá de su creatividad y su experiencia en el campo periodístico, los vínculos de Galeano con los sectores de la izquierda radicalizada también resultaron determinantes para su ascenso a la jefatura de redacción. Se trataba, en buena medida, de una maniobra estratégica. Con ello Quijano apuntaba a aggiornar la retórica de Marcha al viraje ideológico que Cuba había introducido en el continente, aunque desde una paridad de fuerzas al interior del staff que le permitieran sostener el enfoque reformista de la publicación. Algo semejante sucedió en el caso de Época, pese a que Quijano sólo se mantuvo tres meses al frente del periódico. En rigor, Época nació con el objetivo de hacer un aporte al proceso de unificación de la izquierda oriental. Es por eso que la mayoría de sus tendencias contaron con un espacio fijo para expresarse en el cuerpo del diario. Lo mismo puede decirse de la lógica discursiva del proyecto, que se caracterizó por su apertura, su horizontalidad y una permanente convocatoria a unificar posiciones que tuvo a Galeano entre sus defensores más entusiastas. De acuerdo con Rey Tristán (2005), el propio edificio del periódico funcionó como uno de los centros de articulación de los contactos políticos que sentaron las bases para el surgimiento del Frente Amplio en 1971.

Pero en paralelo a estas experiencias, Galeano supo aprovechar otras dos novedades que ofrecía el crecimiento de la industria mediática. La primera fue la irrupción del new journalism, que cambió las formas expresivas del lenguaje periodístico al apelar a una estética que tenía puntos en común con los géneros testimoniales, sobre todo por la asunción de la primera persona, el abandono de la búsqueda de objetividad, el énfasis puesto en la interpretación de los hechos y el empleo de estrategias narrativas propias de la literatura de ficción. Al respecto, en una entrevista realizada para este trabajo, Kovacic (2018) destacó que el autor había leído a los más importantes referentes de la nueva camada de escritores norteamericanos de la década de 1960, sobre todo a Nelle Harper Lee, Gay Talese y Truman Capote, gracias a las recomendaciones de Mario Benedetti y Ángel Rama.

El segundo factor novedoso, en tanto, fue el auge del oficio de corresponsal. Recordemos que en aquellos años se disparó el interés de los lectores por las controversias de un contexto cada vez más convulsionado a causa de la Guerra Fría (1945-1989). Así, las luchas de liberación en el denominado Tercer Mundo, la amenaza latente de un conflicto nuclear entre los Estados Unidos y Rusia, e incluso los cambios 
sociales derivados del desarrollo tecnológico y de la modernización de los códigos estéticos, sexuales, morales, psicológicos y de consumo de la población, traccionaron las inquietudes de la audiencia y facilitaron el despliegue de la intensa literatura de viajes que luego enriqueció la edición de Las venas abiertas de América Latina.

En concreto, en 1963 Galeano recorrió la Rusia postestalinista y la China de Mao Tse-Tung para elaborar su primer libro de crónicas: China, 1964. Crónica de un desafío, en el que analizó las disputas entre las dos potencias comunistas más importantes de la época. Un año más tarde, cubrió los episodios del golpe de Estado contra Joao Goulart en Brasil y realizó su primera visita a Cuba, donde consiguió una entrevista en exclusiva con Ernesto Guevara. Desde entonces, el propósito de sus viajes se orientó a la confección de la obra que lo haría mundialmente famoso. Kovacic (2015) recuerda que los textos de sus recorridos por Chile, España, Estados Unidos, Bolivia, Perú, Venezuela y Guatemala, no sólo se publicaron en su país sino también en distintas revistas internacionales, como por ejemplo las norteamericanas Ramparts y Monthly Review, la yugoslava Politica Internacional, las italianas Mondo Nuovo y Problemi del Socialismo, y las agencias Inter Press Service y Prensa Latina.

Todos estos detalles reflejan el ímpetu con que Galeano intentó convertirse en un actor protagónico dentro del campo intelectual. El esfuerzo que dedicó a esta tarea incluyó la publicación de dos nuevas obras en 1967: la recopilación de cuentos Los fantasmas del día del león y otros relatos, y la crónica Guatemala, clave de Latinoamérica. Así, a casi diez años de que intentara suicidarse, un conjunto de anécdotas muestra que sus aspiraciones comenzaban a rendir frutos. En efecto, en 1968 el tercer fascículo de la colección Capítulo Oriental del Centro Editor de América Latina, lo mencionaba como uno de los autores de «lo nuevo de lo nuevo» en el rubro crónica y ensayo histórico (KOVACIC, 2015, p. 192). A su vez, ese mismo año fue convocado por la editorial Casa de las Américas para participar del Congreso Cultural de La Habana, y dos años más tarde, la institución lo invitó a ejercer como jurado en su certamen anual de distinciones a la literatura de la región. ${ }^{63}$ Estos últimos datos resultan

63 Vale la pena destacar que junto a dicho congreso, las conferencias de la Tricontinental (1966) y de la OLAS (1967) fueron otras de las tantas actividades que organizó el gobierno cubano con el propósito de fortalecer la confianza en el supuesto carácter inminente de la revolución. Si bien no forma parte de los objetivos de este trabajo, recordemos que fue en el trascurso de esas reuniones cuando comenzaron a fragmentarse las posiciones dentro del campo intelectual, 
Vivir para contar:

Trayectoria estético-política de Eduardo Galeano entre 1955 y 1976 | 191 verdaderamente significativos, pues implicaban un reconocimiento a su trayectoria por parte del organismo de legitimación cultural más importante que tenía entonces la izquierda latinoamericana. Se trata de un prestigio que se refrenda en los testimonios de quienes integraron la revista Crisis, cuyas voces dejan en claro la relevancia que había adquirido su figura hacia el final de la década de 1960, sobre todo en los aspectos relativos a la coordinación de proyectos culturales:

Eduardo empezó la dirección de la revista y los contactos latinoamericanos que tenía nos permitían proveernos de abundante material. (...) La facilidad con la que Galeano levantaba el teléfono y conseguía entrevistas o textos originales e inéditos nos daba un plus que nadie tenía (testimonio de Julia CONSTELA, apud, KOVACIC, 2015, p. 223 y 248).

Yo jamás vi a un tipo con la claridad y la rapidez de concepción para resolver periodísticamente un tema como Eduardo Galeano. Era fulminante. Veía una nota y tenía absolutamente claro qué era lo que sobraba o faltaba. Es cierto, Eduardo venía de una experiencia muy fuerte en el semanario Marcha con esa lección permanente de don Carlos Quijano (testimonio de Jorge B. RIVERA, apud KOVACIC, 2015, p. 247).

Con todo, para Galeano el periodismo fue mucho más que un medio de vida y de inserción en el terreno de la cultura. El periodismo fue, además, el ámbito en el que encontró su voz literaria, el estilo particular de su prosa. Tal como sugiere Jorge Ribera, en las redacciones el autor fue descubriendo las señas de identidad de la lógica discursiva que lo convirtió en una pluma visible, característica, una pluma fácil de

debido a la defensa taxativa que Cuba realizó de la lucha armada en tanto herramienta principal y más efectiva de acción política. 
identificar para un público que poco a poco comenzó a interesarse en la lectura de sus textos. En otras palabras, en esos circuitos en los que convivía con autores de la talla de Onetti, Walsh, Rama o Benedetti, Galeano encontró su propia manera de responder dos preguntas esenciales a las que se enfrenta todo periodista: ¿qué debo hacer para atrapar la mirada del lector?, y icómo puedo diferenciarme de mis pares en mi manera de hacerlo?

La clave de su estrategia retórica, como veremos, hay que buscarla en el modo en que Galeano adoptó el registro testimonial. Si bien dicho lenguaje poseía una extensa tradición en las letras del continente, su empleo se revitalizó en la década de 1960 debido a que algunas de sus características lo presentaban como un código atractivo, poderoso y eficaz para elaborar una literatura de combate contra el statu quo. Tanto es así que tras el triunfo de la gesta cubana se publicaron numerosos testimonios guerrilleros, como por ejemplo los Pasajes de la guerra revolucionaria (1963) de Ernesto Guevara. Allí se insertó nuestro escritor con un estilo basado en dos premisas discursivas: el principio ideológico de vivir para contar, en el que nos detendremos en el próximo apartado; y la construcción de una prosa asentada en las tres corrientes de pensamiento más importantes de la época, a saber, las teorías de la dependencia, el existencialismo sartreano y el marxismo humanista de Antonio Gramsci, premisa a la que dedicaremos la última parte del artículo.

\section{Narrar lo inconveniente: la literatura como un ejercicio de oposición al orden establecido}

Retomemos los interrogantes clave de este trabajo. Si dijimos que fue el cruce entre autoritarismo y crisis económica la variable fundamental para el proceso de radicalización del autor, y si a ello agregamos que el correlato artístico de este fenómeno fue la propuesta de una literatura combativa a partir del empleo de los géneros testimoniales, ¿en qué consistió entonces esa estrategia? y ¿cuáles fueron sus características? Según los estudios de John Beverly (1987) y Elzbieta Sklodowska (1992), lo que en principio distingue al testimonio es que escapa a la clasificación habitual entre lo literario y lo no literario, pues su estructura lo hace difícil de asimilar desde las normas tradicionales de la cultura letrada. Y es por eso que dicho registro suele aparecer como una forma anti o contraestética, al tiempo que se describe desde categorías que 
Vivir para contar:

Trayectoria estético-política de Eduardo Galeano entre 1955 y 1976| 193 implican una suerte de oxímoron: socioliteratura, nonfiction novel, novela documental o literatura factográfica, término acuñado por Roque Dalton.

En cuanto a las características de su composición, los autores definen al testimonio como una narración contada en primera persona por un narrador que es a la vez protagonista o testigo de su propio relato. El mismo consiste en una historia real que necesita ser comunicada de manera urgente, pues su origen es un acontecimiento que ha roto los lazos de convivencia: como por ejemplo una represión, un crimen o una situación de explotación o marginalidad. De allí que brinde un punto de vista desde abajo que siempre implica un desafío al statu quo, aun cuando no persiga fines políticos o estos no sean concretos. De acuerdo con Ana María Amar Sánchez (1994), para los escritores que compartían esta perspectiva, la asunción de la primera persona no sólo representaba una prueba contundente de su compromiso con el cambio social, sino también el abandono de todas las pretensiones de elaboración de un discurso neutral u objetivo. Así, estos artistas desarrollaron una nueva lógica estética en base a la articulación de las herramientas del periodismo y la literatura. Se trata de un estilo retórico que Mas'ud Zavarzadeh (1975 y 1976) definió como literatura fictual o bireferencial, en tanto se compone de elementos imaginarios y reales que actúan en conjunto sobre el lector, manteniendo un contrapunto que busca hacer pensar sin dejar de hacer sentir, esto es, que aplica un proceso de montaje con el propósito de que el vínculo entre ficción e investigación periodística potencie el impacto político de los hechos que se relatan.

De modo que no es de extrañar la enorme incidencia que alcanzó el testimonio en tanto género subversivo, en un momento en el que las expectativas revolucionarias proyectaban una profunda revalorización del quehacer intelectual, un cambio que resignificó el ejercicio de las ideas como un acto de intervención transformadora en el ámbito público. Y es por eso que al devolver al escritor a la calle, al instarlo a recuperar la voz de los excluidos y a compartir su misma suerte, esto es, su condición de destinatarios de la violencia estatal, este tipo de discursos se presentaban como la contraparte estética del foco guerrillero. En otras palabras, según las exégesis de Maccioni (2011), Gilman (2012) y Grasselli (2011), mediante su inscripción en el terreno de la realidad, la denuncia de las injusticias del poder y la construcción de un estilo que potenciara la efectividad política de los géneros tradicionales, el escritor aspiraba a contribuir al proceso de toma de conciencia de sus lectores convirtiéndose en una suerte de "Che Guevara del lenguaje", un revolucionario de la 
literatura, según la expresión que patentó Julio Cortázar en la polémica que mantuvo con Oscar Collazos en 1969 (1970, p. 76). ${ }^{64}$

En el caso de Galeano, el género testimonial se hizo presente en sus crónicas a principios de la década de 1960. En ellas, y a partir de las premisas de interpretación, subjetividad y creatividad que distinguían al denominado nuevo periodismo, el autor comenzó a erigir las bases del programa estético que luego trasladaría a sus textos de ficción, donde lo político poco a poco pasó de ser un background, un trasfondo metafórico, a convertirse en la temática principal de su literatura. Lo dicho se materializa en la crónica "El símbolo uruguayo del mal», publicada en 1963, en la que retrata la vida del Cacho, un malhechor que había sido demonizado por la prensa pese a ser inocente de varios de los crímenes que se le imputaban. En estas líneas, Galeano muestra su vocación de contrariar el discurso del poder con el propósito de revelar las tramas ocultas detrás de cada acontecimiento, vocación que ha sido tanto una característica como uno de los aportes más significativos de su obra:

A mediados del 54, hace ya dos años que conoce la picana eléctrica, el caballete, los chalecos de fuerza. (...) Empieza a proteger sus huidas a balazos. (...) El mito se infla sin que importen los hechos ni las causas que los engendraron. Redentores del mundo, honestos ciudadanos sedientos de justicia, seguirán empujando a el Cacho hacia las alucinantes luces y sombras del mundo del hampa. ¿Culpa del destino? No: de las circunstancias. (...) El Cacho es también el Mincho y es tantos otros: habitante de la tierra, no del infierno. (...) El papel pintado de las leyes, poca relación guarda con esta sórdida realidad. (...) Contra el Cacho, se fabricaron más de treinta cargos de rapiña y

${ }^{64} \mathrm{Si}$ bien no nos vamos a detener en esta cuestión, recordemos que dicha impronta perdió legitimidad hacia mediados de la década de 1960, sobre todo tras la realización de la Conferencia Tricontinental de La Habana (1966), cuando comenzaron a imponerse discursos antiintelectuales en el campo cultural latinoamericano. Para más información, consultar los trabajos de Ponza (2010), Gilman (2012), y Maccioni (2011). 
Vivir para contar:

Trayectoria estético-política de Eduardo Galeano entre 1955 y 1976| 195

un desacato (...). Sin embargo, el careo con las víctimas de los robos no dejó lugar a dudas: el Cacho era inocente (GALEANO, 1989, p. 2-4).

Un punto de inflexión en este recorrido fue su visita a Guatemala en 1966. Allí, emulando lo que el periodista argentino Jorge Ricardo Masetti había hecho en Cuba en $1958,{ }^{65}$ Galeano convivió durante dos meses en las montañas con grupos guerrilleros no sólo con el propósito de retratar las injusticias que afectaban al país, sino también con el objetivo de vivirlas en carne propia. Tanto es así que de ahí en adelante sus textos se estructuraron desde el principio de vivir para contar, de ser/estar compartiendo la suerte y las experiencias cotidianas de los excluidos, en tanto prueba de su actitud comprometida con la revolución pero también como estrategia que le permitía incrementar la veracidad de sus relatos. Esto se observa de manera específica en Las venas abiertas de América Latina, donde Galeano volcó una buena cantidad de anécdotas, algunas sumamente riesgosas, en las que intenta mimetizarse dentro de la piel de los obreros, los pobres y los marginados del continente. Un ejemplo revelador es este pasaje de su visita a las minas de la sierra boliviana:

Estábamos muy en lo hondo del cerro Juan del Valle. (...) Recorriendo galerías, habíamos pasado del calor tropical al frío polar y nuevamente al calor, sin salir, durante horas, de una misma atmósfera envenenada. Aspirando aquel aire espeso -humedad, gases, polvo, humo-, uno podía comprender por qué los mineros pierden, en pocos años, los sentidos del olfato y el sabor (GALEANO, 2010, p. 195, el destacado nos pertenece).

\footnotetext{
${ }^{65}$ Masetti fue el primer director de la agencia de noticias Prensa Latina. En 1958 entrevistó a Guevara y a Fidel Castro en medio de la lucha en Sierra Maestra y seis años después, en 1964, murió en la provincia de Salta al comando de las tropas del Ejército Guerrillero del Pueblo (EGP), una de las primeras experiencias de lucha armada en la Argentina.
} 
A su vez, la línea argumental de Guatemala, clave de Latinoamérica (1967), muestra que para entonces el autor ya había radicalizado la perspectiva reformista de su infancia familiar, y comenzaba a adherir a la praxis revolucionaria desde la concepción de la violencia de abajo como respuesta legítima a la violencia de arriba. De esta manera, en uno de los pasajes del libro sostiene que la lucha insurreccional era el correlato de la explotación del orden burgués: "violentas son, en primer término, las condiciones económicas y sociales que condenan a la muerte por hambre o enfermedad a tantos niños de Guatemala. Pero olvidan, además, una diferencia esencial. (...) La violencia de los opresores no puede igualarse a la violencia de los oprimidos" (GALEANO, 1967, p. 24).

En síntesis, fue en el ámbito de la actividad periodística donde Galeano ensayó la progresiva sistematización entre trabajo estético y compromiso político que luego caracterizaría al conjunto de su obra. La prensa gráfica, por lo tanto, operó como plataforma para el desarrollo de sus aptitudes creativas a partir del cruce entre lo que Adriana Falachini (2009) denominó como periodismo de autor, de interpretación y de interpelación. De autor, porque Galeano define sus propias reglas de escritura lejos de las convenciones del periodismo objetivo, para lo cual emplea recursos literarios como la metáfora, la intertextualidad o el tratamiento de los protagonistas como personajes de ficción, a los fines de incrementar el impacto político de los textos. De interpretación, porque los hechos son presentados en el marco de una contextualización profunda, surgida de un sólido cuerpo de antecedentes, con el propósito de describir las causas que los produjeron y sus posibles efectos. Y de interpelación, porque no posiciona al público en el lugar de espectador del relato, sino que éste es convocado a pensarse como parte interviniente y activa frente a los conflictos de la sociedad.

Entonces, pese a que muchos de estos rasgos ya pueden identificarse en Los días siguientes, lo que se potencia en su literatura, debido a la radicalización política, es la dificultad de separar la obra de su contexto. Dicho de otra manera, Galeano se decide por un registro discursivo que busca documentar el momento histórico a través de la memoria colectiva de las calles, los debates y las controversias de una época vertiginosa. De allí que sus trabajos periodísticos y de ficción remitan a una misma temática: el hombre que participa activamente de su tiempo con sus ideas y sus acciones. A estos fines, Galeano violenta las normas tradicionales del arte y del periodismo, a punto tal que el cuento, la novela, la crónica y la entrevista se mixturan y producen una 
Vivir para contar:

Trayectoria estético-política de Eduardo Galeano entre 1955 y 1976| 197

textualidad que respira, explica, duele, indigna y, fundamentalmente, interpela, convoca a los lectores a no quedarse al margen de los acontecimientos para intervenir en la lucha por la construcción del socialismo.

\section{La literatura como foco irradiador de conciencia}

La historia, que ocurrió a mediados de la década de 1990, se la contó al periodista Roberto López Belloso la tercera y última esposa del autor, Helena Villagra, en un reportaje que se publicó en 2016 en Galeano, un ilegal en el paraíso. Ese día, Eduardo acababa de regresar a Montevideo luego de uno de sus frecuentes viajes al exterior. No demoró en dirigirse a su casa; sabía que en la mesa del escritorio le habían dejado una encomienda que esperaba con ansiedad. Cruzó rápido el jardín de la entrada, atravesó el living en el que alguna vez cantaron a dúo Daniel Viglietti y Alfredo Zitarrosa, y se dirigió a la pequeña habitación que utilizaba para escribir. El paquete sobresalía entre sus cuadernillos de anotaciones. Lo tomó con la misma delicadeza con que tomaba la carta que Carlos Quijano le había enviado desde su exilio en Méjico, esa cuya primera línea decía "Querido hijo pródigo...", y que guardaba en un organizador junto a las fotos de Onetti y de Obdulio Varela, el mediocampista que había sido capitán y héroe de la selección uruguaya en la copa del mundo de 1950. Eduardo esperó un momento antes de abrir el paquete. El sobre contenía un ejemplar de la segunda edición de Las venas abiertas de América Latina. Al tomarlo entre sus manos, observó la rajadura en el centro de la tapa. Dio vuelta el libro con temor, y notó que el tajo lo había atravesado por completo. El ejemplar pertenecía a un joven militante de la guerrilla salvadoreña que lo llevaba en su mochila cuando fue asesinado en 1984. Los militares le dispararon por la espalda y la herida fue mortal. Las casi cuatrocientas páginas del libro no fueron suficientes para detener la bala.

La anécdota resume las expectativas que los escritores revolucionarios depositaban en la literatura, al tiempo que recuerda el fracaso de proyectos de cambio social que no lograron o no supieron construir una opción de poder hegemónico para los sectores populares del continente. Como hemos visto, Galeano asumía el ejercicio estético como una forma de acción política. La literatura era para él una tarea militante que debía revelar las condiciones de opresión y, al mismo tiempo, subvertir el canon de la cultura burguesa. Desde su óptica, 
entonces, el arte era una praxis capaz de provocar una profunda transformación en la conciencia sometida del hombre, esto es, un cambio en la subjetividad del lector que lo llevaría a romper su consentimiento con el sistema capitalista. De allí que considerara a la literatura como un arma cargada de verdades que podía hacer estallar el sustento ideológico de la dominación.

Precisamente, Las venas abiertas de América Latina marcó un momento decisivo en la trayectoria de Galeano hasta 1976, porque en sus páginas se cierra el proceso de traducción de su pensamiento político a una estrategia concreta de escritura. El libro constituye el punto de máxima sinergia entre el objetivo de transformar el orden y la elección de un conjunto de pautas, o bien de tácticas estéticas, con las que Galeano aspiraba a incidir en la conciencia del lector. Nos referimos, con esto, al vínculo entre las corrientes de pensamiento del existencialismo sartreano, el marxismo humanista de Gramsci y las teorías de la dependencia, con lo que al principio calificamos como una propuesta literaria asentada en tres ejes: compromiso político, elección de géneros realistas e intervención protagónica en el ámbito público, de lo cual dos entre varios ejemplos fueron sus incursiones en Bolivia y Guatemala, pese a que en general puede decirse que, sobre todo en Las venas..., Galeano describe y reescribe el mapa subalterno del continente con sus propios ojos, con su propio cuerpo.

En cuanto a las exégesis de Sartre y Gramsci, estas se plasman en sus textos mediante tres premisas. Las dos primeras, que ya hemos mencionado, eran la necesidad de dar una batalla en el terreno de la cultura para romper la hegemonía política de la clase dominante, y el principio de vivir para contar, que consistía en la caracterización del hombre de ideas como un sujeto comprometido con la resolución de las injusticias que afectaban a la sociedad de su tiempo. A estas hay que añadir la puesta en valor de lo nacional-popular, que pasó a considerarse una experiencia genuina de la historia y de la cultura latinoamericana, en contraposición con lo foráneo o antinacional, que se asociaba a los intereses económicos y las políticas autoritarias de las burguesías y el imperialismo. En efecto, esta última premisa se articula en Las venas... a partir del contraste entre el ethos supuestamente revolucionario, justo y legítimo de las clases subalternas, y la actitud entreguista de una aristocracia que no dudaba en recurrir a la fuerza para resguardar sus privilegios: 
Vivir para contar:

Trayectoria estético-política de Eduardo Galeano entre 1955 y 1976| 199

Los fantasmas de todas las revoluciones estranguladas o traicionadas a lo largo de la torturada historia latinoamericana se asoman en las nuevas experiencias, así como los tiempos presentes habían sido presentidos y engendrados por las contradicciones del pasado (GALEANO, 2010, p. 22).

Al sur, José Artigas encarnó la revolución agraria. Este caudillo, con tanta saña calumniado y tan desfigurado por la historia oficial, encabezó a las masas populares de los territorios que hoy ocupan Uruguay y las provincias argentinas de Santa Fe, Corrientes, Entre Ríos, Misiones y Córdoba, en el ciclo heroico de 1811 a 1820 (...). Luchó contra los españoles y los portugueses, y finalmente sus fuerzas fueron trituradas por el juego de pinzas de Río de Janeiro y Buenos Aires, instrumentos del Imperio británico, y por la oligarquía que, fiel a su estilo, lo traicionó no bien se sintió, a su vez, traicionada por el programa de reivindicaciones sociales del caudillo (GALEANO, 2010, 153).

Esta retórica del contraste, constituye el principio de exposición formal desde el que se organiza la estructura de la obra. Así, el modo en que Galeano expone su interpretación de las teorías de la dependencia, también está mediado por el empleo de este recurso. Recordemos que estas corrientes atribuían el subdesarrollo de los países de la región, por un lado, a un esquema político-económico de orden mundial que otorgaba facilidades a ciertos países para apropiarse de los bienes de la periferia, y, por otro, al hecho de que ese mismo esquema se replicaba dentro del territorio latinoamericano, pues las clases dominantes obtenían beneficios de dicha situación y obraban en connivencia con los centros capitalistas. De modo que la pobreza y el subdesarrollo eran descriptos como el sine qua non de la concentración de la riqueza y el poder, es decir, como un fenómeno político que exigía cambios globales 
en el mismo sentido, cambios que convertían a la política de Estado -y en definitiva al propio Estado- en la llave maestra de las soluciones.

En concreto, el autor elabora su discurso desde una lógica de espejos confrontados, con el propósito de señalar la continuidad en el presente tanto de las formas de saqueo y sometimiento que signaban al imperialismo, como así también de una histórica tradición de lucha popular que se consideraba vigente en los movimientos revolucionarios. Esta suerte de metodología revisionista se traducía en una contextualización hacia atrás, que apuntaba a inscribir los sucesos de la época en la tesis filosófica del eterno retorno, o en todo caso en la lectura que Galeano hacía de ella; esto es, en la permanente repetición de un pasado de injusticias pero también de enfrentamientos contra el poder, que demostraban que el pueblo no era un actor pasivo y que podía revelarse una vez más contra las fuerzas del orden:

Nuestra derrota estuvo siempre implícita en la victoria ajena; nuestra riqueza ha generado siempre nuestra pobreza para alimentar la prosperidad de otros: los imperios y sus caporales nativos. (...) simétricamente, el bienestar de nuestras clases dominantes -dominantes hacia dentro, dominadas desde fuera- es la maldición de nuestras multitudes condenadas a una vida de bestias de carga (GALEANO, 2010, p. 15).

Pero no está tan lejos en el tiempo, al fin y al cabo, la explosión mística de los nordestinos que pelearon junto a sus mesías, (...) alzando la cruz y los fusiles contra los ejércitos, para traer a esta tierra el reino de los cielos, ni las furiosas oleadas de violencia de los cangaceiros: los fanáticos y los bandoleros, utopía y venganza, dieron cauce a la protesta social, ciega todavía, de los campesinos desesperados (GALEANO, 2010, p. 167).

Esta yuxtaposición de acontecimientos y figuras del pasado y del presente, se repite de manera incesante a lo largo de Las venas... La rebeldía de Túpac Amaru o de José Gervasio Artigas contra los españoles, 
Vivir para contar:

Trayectoria estético-política de Eduardo Galeano entre 1955 y 1976| 201

vuelve a nacer en la lucha de la Revolución Cubana contra el imperialismo norteamericano, y al hacerlo configura la imagen de un proceso siempre en marcha, siempre en movimiento y cada vez más próximo al triunfo socialista; un recorrido temporal protagonizado por dos bloques homogéneos entre los cuales supuestamente no existía -ni había existido, ni existiría nunca- otro vínculo más que el de una perpetua confrontación.

Asimismo, esta retórica del contraste organiza la estructura de la obra incluso en los aspectos primarios de su composición formal. De hecho, Galeano suele construir las oraciones mediante frases contrapuestas a veces de manera afirmativa -"Perdimos; otros ganaron. Pero ocurre que quienes ganaron, ganaron gracias a que nosotros perdimos"- y otras entre signos de interrogación: “Es América Latina una región del mundo condenada a la humillación y a la pobreza? ¿Condenada por quién? ¿Culpa de Dios, culpa de la naturaleza? (...) ¿No será la desgracia un producto de la historia, hecha por los hombres y que por los hombres puede, por lo tanto, ser deshecha?" (GALEANO, 2010, p. 16 y 340). En estos ejemplos se destaca, además, otro de los recursos formales de la obra: el empleo de la ironía, que reafirma el mensaje político del autor y lo convierte en lo que Palaversich (1995, p. 145) define como un "historiador subversivo», un intelectual que desarma los mitos sobre el subdesarrollo latinoamericano al tiempo que se ríe de las clases dominantes de la región.

Finalmente, otros recursos estéticos muy utilizados en Las venas... son la intertextualidad y la transgenericidad. El primero abarca el enorme bagaje de fuentes que el autor utiliza para sustentar sus ideas, como así también el estilo literario que toma de otros escritores para incrementar la posibilidad de que el lector pueda reconocerse en su texto. Un ejemplo es el vínculo con la prosa sencilla, coloquial y sin pretensiones sociológicoacadémicas que aplica Mario Benedetti en El país de la cola de paja (1960). Dicha prosa es a su vez signo de un género literario de larga tradición en el continente: el ensayo de ideas, que agrupa autores como José Martí, José Enrique Rodó, José Carlos Mariátegui o Roberto Fernández Retamar, con quienes Galeano comparte cierta afinidad temática y, ante todo, la férrea esperanza en un destino de utopía: la promesa de la futura emancipación de los sectores populares latinoamericanos.

Otro ejemplo en el mismo sentido es la búsqueda de un lenguaje gráfico y contundente, que el autor parece tomar de la eficacia retórica del Manifiesto comunista (1848). Detengámonos, al respecto, en la primera 
frase de Las venas...: "La división internacional del trabajo consiste en que unos países se especializan en ganar y otros en perder” (GALEANO, 2010, p. 15); ¿acaso no es evidente el paralelo con la famosa sentencia que da inicio a la obra de Marx?: "La historia de toda sociedad hasta nuestros días no ha sido sino la historia de las luchas de clases" (MARX, 2000, p. 25). En efecto, es la misma prosa enardecida buscando encender políticamente a los lectores. Y no se trata de una mera casualidad, pues el ímpetu con el que encaró este trabajo, el tiempo que le dedicó y los riesgos que supo correr en sus incursiones periodísticas, parecen indicar que Galeano aspiraba a convertir a Las venas... en el manifiesto latinoamericano del siglo XX.

Por su parte, el recurso de la transgenericidad se utiliza en los momentos en los que el autor busca incrementar la intensidad del relato. Para ello se vale de ciertas herramientas que toma de la literatura de ficción, como el uso de metáforas, ciertos tipos y maneras de adjetivar, y sobre todo la construcción de escenas que remiten a los géneros tradicionales. Ejemplo de esto último es la citada descripción de la actividad minera en Bolivia, donde el texto pivotea entre el relato fantástico, el terror psicológico y el surrealismo, a los fines de retratar el presente de la sociedad capitalista de la década de 1970 como una realidad inverosímil, abstracta, carente de toda lógica. Una realidad hipertrofiada por la voraz explotación de la riqueza, que hacía que la hojalata no fuera solamente "un símbolo pop de los Estados Unidos", sino además "un símbolo, aunque no se sepa, de la silicosis en las minas [de] Huanuni", donde los mineros morían "con los pulmones podridos" para que el mundo pudiera consumir estaño barato (GALEANO, 2010, p. 193):

Estábamos muy en lo hondo del cerro Juan del Valle. (...) Recorriendo galerías, habíamos pasado del calor tropical al frío polar y nuevamente al calor, sin salir, durante horas, de una misma atmósfera envenenada. (...) Los cascos guardatojos irradiaban un revoloteo de círculos de luz que salpicaban la gruta negra y dejaban ver, a su paso, cortinas de blanco polvo denso: el implacable polvo de sílice. El mortal aliento de la tierra va envolviendo poco a poco. Al año se sienten los primeros síntomas, y en diez años se ingresa al 
Vivir para contar:

Trayectoria estético-política de Eduardo Galeano entre 1955 y 1976 | 203 cementerio. Dentro de la mina se usan perforadoras suecas último modelo, pero los sistemas de ventilación y las condiciones de trabajo no han mejorado con el tiempo. (GALEANO, 2010, p. 195, el destacado nos pertenece).

En síntesis, esta estrategia de cruce entre historia y presente, estética y política, compromiso y acción, y periodismo y literatura, le permitió trabajar de manera creativa sobre sentidos comunes profundamente arraigados en el imaginario de los sectores progresistas y de izquierda del continente. A través de ella Galeano logró establecer un poderoso vínculo de complicidad ideológica con sus lectores, que se resume de manera brillante en la metáfora que da título a la obra: la imagen de América Latina como una mujer ultrajada y con sus venas abiertas en beneficio del imperialismo. Dicha estrategia, por lo tanto, constituye un factor clave para determinar por qué el libro se transformó en un fenómeno cuyo volumen de ventas se ha sostenido en el tiempo, en buena medida también coadyuvado por el hecho de que las problemáticas que analiza tampoco han perdido vigencia.

Con todo, el talento de Galeano no fue suficiente para garantizar el éxito de la obra. De hecho, éste se hizo esperar: el libro se publicó en 1971 y apenas vendió quinientos ejemplares en su primera edición. Tanto es así que el primer cheque por derechos que recibió de la editorial Siglo XXI, llegó acompañado de una carta en la que los directivos del sello lo alentaban a seguir escribiendo y a no desanimarse. "Mis amigos más queridos me trataron con indulgencia. Me dijeron, está bien, (...) pero esto es algo que no puede ser tomado en serio”, recordaba Galeano sobre las primeras críticas que recibió su obra (PALAVERSICH, 1995, p. 142). Por suerte para él, sus amigos y la editorial se equivocaban: con el correr de los años, Las venas... se transformó en un fenómeno que ha vendido más de dos millones de ejemplares solo en sus ediciones de habla hispana, según afirmó el responsable actual de Siglo XXI, Jaime Labastida, en un reportaje con la periodista Mónica Mateos-Vega (2016).

¿Qué fue entonces lo que sucedió? ¿Qué otra variable hizo posible el éxito de la obra? La respuesta está en las nuevas vías de consagración que habilitaron las redes intelectuales. De acuerdo con los estudios que hemos citado hasta aquí, la extensa trama de revistas y diarios que floreció en la década de 1960, ofreció un espacio de legitimación alternativa al de 
las instituciones de la cultura oficial. Y esto no sólo porque el escritor encontró en dicho espacio un soporte para hacer visible su palabra, para manifestar su compromiso con la crítica al poder, sino además porque desde allí pudo entrar en diálogo con otros intelectuales, difundir sus obras y debatir cuáles eran las estrategias de escritura que mejor se asociaban a los objetivos de transformación política.

No es de extrañar, entonces, que junto a su estrategia de escritura Galeano implementara una estrategia de difusión de largo aliento para incrementar las posibilidades de recepción del libro. Entre las huellas tácticas de esa estrategia se destacan, por un lado, la publicación de varios pasajes de la obra en distintas revistas y medios de orden internacional, proceso que ya hemos señalado y que el autor comenzó a llevar adelante en 1968. A ello siguió su presentación al primer certamen del concurso literario de Casa de las Américas en la categoría Testimonio (1970), que tuvo como ganadora a María Esther Gilio con un trabajo sobre la guerrilla tupamara, y en el que Las venas... logró una mención especial. Y por último, Kovacic (2015 y 2018) destaca el papel determinante que jugó la red de contactos de Galeano en la difusión boca en boca del libro. De ello se encargaron, por una parte, los comentarios elogiosos de Vivian Trías, Darcy Ribeiro, Rogelio García Lupo y otros intelectuales que colaboraron en la confección de la obra. También el semanario Marcha hizo su aporte con una extensa entrevista al autor que se publicó el 6 de agosto de 1971. Y finalmente, la editorial envió ejemplares a distintos sellos para que los hicieran circular entre los escritores del continente. Todo esto muestra el ímpetu de Galeano por convertirse en una figura de referencia dentro del campo cultural, circunstancia para la que sin dudas resultaría clave el éxito rotundo -y ahora sí inmediato- de la revista Crisis.

Es por eso que el paulatino ascenso de Las venas... refrenda la hipótesis de Claudia Gilman (2012) sobre lo clave que resultaron las redes de relaciones para el posicionamiento de los hombres de ideas. Fenómenos de consagración horizontal como el texto de Galeano o Cien años de soledad, dan cuenta de la fortaleza del entramado construido tras el triunfo de la Revolución Cubana. Desde nuestro punto de vista, una y otra obra pueden pensarse como el momento cumbre de las dos representaciones del escritor comprometido que entrarían en colisión hacia finales de la década de 1960: la del novelista experimental y la del escritor que buscaba en el testimonio una herramienta superadora de la primera, que acabó por concebirse como una expresión del arte burgués hecha a la medida del mercado. 


\section{Consideraciones finales}

Las circunstancias políticas que signaron a la Banda Oriental entre 1955 y 1976, fueron el principal leudante del proceso de radicalización que vivió Eduardo Galeano en el curso de ese período. El implemento de una alternativa de liberalización conservadora, que sólo podía afrontar los conflictos derivados del colapso económico a partir de la expansión de las prácticas de ajuste, recorte de derechos civiles y represión de la protesta social, lo condujo a erigir un pensamiento que pasó de la crítica al sistema capitalista y sus instituciones, a la definición de la vía revolucionaria en tanto único medio eficaz para la transformación del orden vigente.

Desde esta óptica, la idea de que el campo cultural era un escenario clave en la lucha por el poder, debido al carácter hegemónico de la dominación, llevó a que Galeano asumiera la literatura como una tarea militante cuyo propósito era coadyuvar a subvertir la conciencia sometida del público, a los fines de romper su consentimiento ideológico con el régimen capitalista. Para ello era necesario diagramar una estrategia discursiva que conmoviera intelectual y afectivamente a los lectores; una estrategia capaz de indignarlos frente a las formas de explotación, violencia y miseria que afectaban al continente. La misma consistió en el trabajo sobre sucesos de actualidad; la asunción de la primera persona como testimonio del compromiso del autor; su intervención concreta en el ámbito público a través de actos de militancia que nutrían su literatura; la toma de distancia con las pretensiones de una estética neutral u objetiva; la impugnación explícita del sistema y el papel protagónico otorgado al ciudadano común en tanto fuente de la problemática abordada.

De esta manera, el acto de articular el testimonio como una reescritura de la Historia, constituía una estrategia de lucha peligrosa o de aspiración revolucionaria por dos motivos. Primero, porque refutaba la versión oficial de los hechos del presente y del pasado, calificándola como una mentira o una manipulación fraguada por el orden burgués con el fin de resguardar sus intereses. Y segundo, porque con ello no sólo se legitimaba una representación contrahegemónica de esos hechos, sino también la imagen de la cultura como un campo de batalla en el que era necesario intervenir a contracorriente. Así, el rescate de la voz de los excluidos apuntaba tanto a visibilizar las condiciones de pobreza como a justificar las acciones de los activistas revolucionarios. Dicho en otras 
palabras, la contraposición entre las perspectivas de abajo y las voces del orden dominante, se transformaba en el correlato discursivo de la contraposición entre la violencia popular y la violencia de los de arriba.

Instrumento de un programa estético que a su vez buscaba aportar a la constitución de un nuevo hombre, es decir, de un sujeto libre y emancipado de las leyes del valor y de la mercancía, esta estrategia no explica por sí sola el éxito que cosechó Galeano en la década de 1970. A ella es necesario agregar su tránsito por medios periodísticos que enriquecieron su formación político-literaria, que le aportaron una enorme cantidad de vínculos que jugaron un papel clave en su inserción en el campo cultural, y que sobre todo le hicieron sentir que formaba parte de una potente trama afectiva. Pues los espacios materiales de la redes, además de ofrecer vías para la sistematización entre trabajo estético y compromiso político, también funcionaron como comunidades experimentales en las que el escritor parece haber podido vivir el sentimiento de emergencia de ese nuevo hombre y esa nueva sociedad. Espacios en los que el desarrollo de un horizonte utópico en común, de una esperanza compartida, parece haber obrado como aliciente de la actividad política y del afán de los intelectuales por ocupar un rol protagónico en ese proceso. Un aliciente que se relacionó en forma tan íntima con la reproducción de las expectativas transformadoras, que su pérdida en la noche de las dictaduras constituyó un desafío sumamente difícil de sobrellevar para los sobrevivientes.

\section{BIBLIOGRAFÍA}

ALABARCES, Pablo. Walsh: dialogismos y géneros populares. En: Jorge LAFFORGUE (Ed.) Textos de y sobre Rodolfo Walsh. Buenos AiresMadrid: Alianza, 2000: 29-39.

AMAR SÁNCHEZ, Ana María. La propuesta de una escritura (En homenaje a Rodolfo Walsh). En: Roberto BASCHETTI. (Ed.) Rodolfo Walsh, vivo. Buenos Aires: Ediciones de la Flor, 1994: 431445.

BADIOU, Alan. El siglo. Buenos Aires: Ediciones Manantial, 2005.

BEIGEL, Fernanda. Las revistas culturales como documentos de la historia latinoamericana. En Utopía y Praxis Latinoamericana, vol. 8, $n^{\circ}$ 20. Venezuela: Universidad del Zulia, 2003: 105-115.

BENEDETTI, Mario. El país de la cola de paja. Montevideo: Arca, 1966. 
Vivir para contar:

Trayectoria estético-política de Eduardo Galeano entre 1955 y 1976| 207

BENEDETTI, Mario. La tregua. Buenos Aires: Sudamericana, 2000.

BEVERLEY, John. Anatomía del testimonio. En Revista de Crítica Literaria Latinoamericana, vol. 13, n 25. Lima: Centro de Estudios Literarios Antonio Cornejo Polar, 1987: 7-16.

COLLAZOS, Oscar; Cortázar, Julio y Vargas Llosa, Mario. Literatura en la revolución y revolución en la literatura (polémica). México: Siglo XXI, 1970.

DEMASI, Carlos. La caída de la democracia, Cronología comparada de la historia reciente del Uruguay (1967-1973). Montevideo: Fundación de Cultura Universitaria, 1996.

FALCHINI, Adriana. Dejo constancia. Francisco "Paco" Urondo, ese cronista. En: Analía GERBAUDO y Adriana FALCHINI. (Comps.) Cantar junto al endurecido silencio. Escritos sobre Francisco Urondo. Santa Fe: Universidad Nacional del Litoral, 2009: 145194.

FILGUEIRA, Fernando (et all). Los dos ciclos del Estado uruguayo en el siglo XX. En: Benjamín NAHUM y Gerardo CAETANO. (Coords.) El Uruguay del siglo XX, tomo 2. Montevideo: Ediciones de la Banda Oriental, 2003. p. 173-204.

GALEANO, Eduardo. China, 1964. Crónica de un desafío. Buenos Aires: Jorge Álvarez, 1964.

GALEANO, Eduardo. Días y noches de amor y de guerra. Rosario: Biblioteca Era, 2000.

GALEANO, Eduardo. Guatemala un país ocupado: ¿Un presentimiento de Vietnam? Marcha, n 1367. Montevideo, 1967.

GALEANO, Eduardo. Las venas abiertas de América Latina. Buenos Aires: Siglo XXI, 2010.

GALEANO, Eduardo. Los días siguientes. Montevideo: Alfa, 1963.

GALEANO, Eduardo. Los fantasmas del día del león y otros relatos. Montevideo: Arca, 1967.

GALEANO, Eduardo. Nosotros decimos no. Buenos Aires: Siglo XXI, 1989.

GILMAN, Claudia. Entre la pluma y el fusil. Buenos Aires: Siglo XXI, 2012.

GIUNTA, Andrea. Vanguardia, internacionalismo y politica. Buenos Aires: Siglo XXI, 2008.

GOLDGEL, Víctor. Cuando lo nuevo conquistó América. Buenos Aires: Siglo XXI, 2013.

GRAMSCI, Antonio. Antología. Buenos Aires: Siglo XXI, 2013. 
GRASSELLI, Fabiana. Rodolfo Walsh y Francisco Urondo, el oficio de escribir. Tensiones y respuestas de una literatura peligrosa: prácticas estéticopoliticas y escritura testimonial. Buenos Aires: Editorial de la Facultad de Ciencias Sociales de la Universidad de Buenos Aires, 2011.

IGLESIAS, Mariana. La excepción como práctica de gobierno en Uruguay, 1946-1973. Contemporánea. Historia y problemas del siglo XX, vol. 2, año 2. Montevideo, 2011: 137-155.

KOVACIC, Fabián. Galeano, la biografía, Buenos Aires: Vergara, 2015.

LADDAGA, Reinaldo. Estética de la emergencia. Buenos Aires: Adriana Hidalgo, 2006.

LÓPEZ Belloso, Roberto. (Ed.) Galeano, un ilegal en el paraíso. Buenos Aires: Siglo XXI, 2016.

MACCIONI, María Laura. Lineas de fuga. Literatura y política en Reinaldo Arenas y Juan José Saer (1960-1975). Estados Unidos: Universidad de Maryland, 2011.

MAÍZ, Claudio. Las re(d)vistas latinoamericanas y las tramas culturales: Redes de difusión en el romanticismo y el modernismo. Cuadernos del CILHA, n 14. Mendoza: Universidad Nacional de Cuyo, 2011: 75-91.

MARCHESI, Aldo y YAFFÉ, Jaime. La violencia bajo la lupa. Una revisión de la literatura sobre violencia y política en los sesenta. Revista uruguaya de Ciencia Política, vol. 19, $\mathrm{n}^{\circ} 1$. Montevideo, 2010: 95-118.

MARX, Carl. El manifiesto comunista. Buenos Aires: Ediciones el Aleph, 2000. Disponible en Internet en $<$ https://sociologia1unpsjb.files.wordpress.com/2008/03/marxmanifiesto-comunista.pdf $>$

MATEOS-VEGA, Mónica. Medio Siglo de Siglo XXI Editores. La jornada, edición correspondiente al sábado 24 de septiembre. México DF, 2016. p. 3, disponible en Internet en <http://www.jornada.unam.mx/2016/09/24/cultura/a03n1cul>

NAHUM, Benjamín. (Coord.) Crisis politica y recuperación económica. Montevideo: Ediciones de la Banda Oriental, 1998.

NERCESIAN, Inés. La política de las armas y las armas de la política, Brasil, Chile y Uruguay 1950/1970. Buenos Aires: CLACSO, 2013.

PALAVERSICH, Diana. Silencio, voz y escritura en Eduardo Galeano. Madrid: Iberoamericana, 1995.

PONZA, Pablo. Intelectuales y violencia política 1955-1973, Córdoba: Babel, 2010. 
Vivir para contar:

Trayectoria estético-política de Eduardo Galeano entre 1955 y 1976| 209

REY TRISTÁN, Eduardo. A la vuelta de la esquina. La izquierda revolucionaria uruguaya 1955-1973. Sevilla: Consejo Superior de Investigaciones Científicas de la Universidad de Sevilla, 2005.

RIBADERO, Martín. Intelectuales, política y violencia: el semanario Marcha en la década de 1960. En: Waldo ANSALDI y Verónica GIORDANO. (Coords.) América Latina. Tiempos de violencias. Buenos Aires: Ariel, 2014: 261-279.

SARTRE, Jean-Paul. ¿Qué es la literatura? Buenos Aires: Losada, 2008.

SKLODOWSKA, Elzbieta. Testimonio hispanoamericano: historia, teoría y poética. New York: Lang Publishing, 1992.

SIMMEL, Georg. Cuestiones fundamentales de sociología. Barcelona: Gedisa, 2002.

TCACH, César. Entre la lógica del partisano y el imperio del Gólem: dictadores y guerrilleros en Argentina, Brasil, Chile y Uruguay. En: Hugo QUIROGA y César TCACH. (Comps.) Argentina 19762006. Entre la sombra de la dictadura y el futuro de la democracia. Rosario: Homo Sapiens, 2006: 123-166.

ULANOVSKY, Carlos. Paren las rotativas (1970-2000). Buenos Aires: Emece, 2005.

WALSH, Rodolfo. Operación masacre. Buenos Aires: Ediciones de la Flor, 1957. Disponible en Internet en <http://proyectowalsh.com.ar/wp/wpcontent/uploads/2010/12/Walsh-Rodolfo-OperacionMasacre.pdf>

ZAVARZADEH, Mas'ud. The Apocalyptic Fact and the Eclipse of Fiction in Recent American Prose Narratives. Journal of American Studies, vol. 9, n 1. Reino Unido: Universidad de Cambridge, 1975: 6983.

ZAVARZADEH, Mas'ud. The mythopoeic reality. The postwar American nonfiction novel. Estados Unidos: Universidad de Illinois, 1976.

\section{Fuentes consultadas}

KOVACIC, Fabián. Entrevista realizada el 15 de abril de 2018.

Semanario Marcha (Montevideo, 1939-1974), números 640, 726-727, 769. $770,930-945,1367,1413-1418,1555-1560,1571-1573,1587-$ 1591 y $1645-1650$.

Revista Crisis (Buenos Aires, 1973-1976), números 1 al 40. 
Recebido em: 10/07/2018

Aceito em: 29/07/2018 